\title{
Domesticando el despojo: palma africana, acaparamiento de tierras y género en el Bajo Aguán, Honduras
}

\author{
Domesticating Dispossession: African Palm, \\ Land Grabbing and Gender in the Bajo Aguán, Honduras
}

\author{
Andrés León Araya \\ Universidad de Costa Rica \\ a.leonaraya@gmail.com
}

\begin{abstract}
RESUMEN
Con base en el testimonio de vida de una familia campesina, este artículo explora la contrarreforma agraria, entendida como un proceso de acumulación primitiva, que se llevó a cabo a principios de los noventa en Honduras. Más específicamente, se busca recuperar la vivencia compartida de muchas mujeres campesinas a través de una perspectiva etnográfica y de género que proporcione ciertas luces sobre cómo opera el despojo, en tanto proceso permanente y constitutivo del capitalismo.
\end{abstract}

Palabras clave: despojo, acumulación primitiva, reforma agraria, género, Honduras.

\begin{abstract}
$\overline{\text { ABSTRACT }}$
From the perspective of a peasant family, this article explores the agrarian counter reform that took place in Honduras in the early 1990s, as a process of primitive accumulation. Specifically, it attempts to recuperate the shared experience of many peasant women through an ethnographic and gendered perspective, which sheds some lights on how dispossession, defined as a permanent and constitutive process of capitalism, operates.
\end{abstract}

Keywords: dispossession, primitive accumulation, agrarian reform, gender, Honduras. 


\section{Introducción}

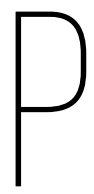

ara Eugenia el principio del fin - es decir, la venta de las tierras de la cooperativa a la que ella y su esposo habían estado afiliados-comenzó con las vacas. Ella lo recuerda bien. A mediados de los ochenta la cooperativa de reforma agraria de la que hacía parte con su esposo, Marino, había comprado alrededor de diez vacas lecheras que rotaban entre las diferentes familias asociadas. Así, por dos días cada familia cuidaba las vacas y por dos días tenían leche para sus hijos.

¡Ah! Y yo me alegraba cuando los niños iban con sus panitas a traer su lechita para comer y pues no, cuando ya intentan vender la cooperativa entonces dicen: "No, no, no, hay que vender las vacas, porque esta palmera ${ }^{1}$ se va a vender y hay que vender a las vacas”... Y yo estaba en contra...

La discusión sobre la posible venta de las tierras de la cooperativa —homologada con las palmeras de palma africana- había empezado algunos años antes, pero no fue sino hasta que las vacas fueron amenazadas, a mediados de 1990, que Eugenia, así como otras mujeres, comprendieron lo que estaba en juego. Poco tiempo después ella empezaría una cruzada que la llevaría a través de todo el valle del Aguán, en la costa norte de Honduras, en búsqueda de aliados que la ayudaran en su lucha en contra de la venta de las tierras y, por tanto, de las vacas. En términos prácticos sus esfuerzos fracasaron y, para finales de 1990, la vida cotidiana y el paisaje de la región habían sido profundamente transformados. Sin embargo, en términos analíticos, la lucha de Eugenia se puede utilizar para ilustrar y explorar el proceso complejo, conflictivo y multiescalar que llevó a la concentración de alrededor de dos tercios de la tierra que se había distribuido durante el periodo de reforma agraria en Honduras (1972-1992), una de las más grandes en América Latina (Kay 1998), entre un grupo limitado de terratenientes y empresas transnacionales (Cococh 2010; Macías 2001).

En términos generales, este proceso de contrarreforma agraria en Honduras ha sido estudiado desde perspectivas que se centran en los motivos y las formas en que las cooperativas - entendidas unitaria y formalmente-perdieron o vendieron sus tierras. El resultado ha sido una lectura política profundamente masculinista, en la que se invisibiliza la experiencia de las mujeres, en dos direcciones en particular. Primero, esfuerzos como el de Eugenia en contra de las 
ventas nunca se incluyen en los análisis, lo que niega su papel tanto en las luchas como en la reproducción de la vida en las comunidades. Segundo, al tomar a las cooperativas como organizaciones homogéneas, se esconde el hecho de que hay diferentes personas ubicadas en distintas posiciones con respecto a los procesos políticos y económicos más amplios - el despojo de las tierras en este caso-y que estas diferencias, ya sean de género, clase o edad, también tienen mucho que decirnos sobre las lógicas mismas del despojo² y de los modos como se forman las clases sociales (Brewer 1999; Crehan 1997; Federici 2004; Mackintosh 1989; Massey 2013; Scott 1999; Stolcke 2010).

La literatura reciente sobre el tema del acaparamiento de tierras (land grabbing) ha recibido críticas similares (Behrman, Meinzen-Dick y Quisumbing 2012; Chu 2011; Ojeda 2012). Además, se ha cuestionado la ausencia de una mayor atención a temas como las trayectorias históricas de dichos procesos de despojo (Edelman y León 2014), las dinámicas laborales que generan y transforman (Li 2011), así como los tipos de respuestas concretas que se dan por parte de sujetos (individuales y colectivos) particulares (Hall et al. 2015). En este sentido, lo que planteo aquí es explorar la contrarreforma agraria de principios de los noventa en Honduras, entendida como un proceso de acumulación primitiva, a partir de un acercamiento que privilegia la experiencia de quienes lo vivieron de forma más directa y que, sin saberlo, quedaron atrapados en una red de procesos económicos y políticos que operan en distintas escalas y temporalidades. Más específicamente, mi interés es recuperar, desde el interior de esta desordenada trama de sucesos y dinámicas - a través de la historia específica de Eugenia-, la experiencia compartida y vivida por muchas otras mujeres campesinas. Mi propuesta es que, mediante una perspectiva etnográfica centrada en lo que las personas están haciendo en un momento concreto, y de género, que parte del hecho de que hombres y mujeres viven estos procesos de forma articulada y diferenciada, es posible mostrar cómo opera el despojo que, además de ser permanente y constitutivo del capitalismo, es un proceso diferenciado por posición de género y clase.

Para explicar lo anterior es necesario mostrar la forma en la cual los distintos elementos de esta historia -incluyendo las vacas, las palmeras y hasta a

2 En la última década, el concepto de despojo ha ganado una gran popularidad y se viene utilizando de distintas maneras para hacer referencia a una gran cantidad de procesos políticos, económicos y sociales. Más adelante definiré claramente cómo empleo dicha noción. De momento es suficiente mencionar que me aproximo al despojo desde la discusión marxista sobre la acumulación primitiva u originaria, y que lo entiendo como un proceso constante y constitutivo del capitalismo en el que el trabajo viviente de las clases trabajadoras es apropiado o capturado por el capital por medios extraeconómicos (véanse, por ejemplo, De Angelis 2004; Grandia 2009; Perelman 2000). 
Eugenia- llegaron a articularse como lo estaban en el Bajo Aguán, a principios de la década de los noventa.

Este artículo está organizado en cuatro secciones. Primero, describiré de forma rápida el Bajo Aguán, escenario de esta historia. Luego me concentraré en la historia de migración de Eugenia y su esposo, Martino, en la década de los ochenta, de la zona de Copán, en el occidente del país, hasta el Bajo Aguán. En un tercer momento relataré la llegada del matrimonio al Aguán, su ingreso a la cooperativa palmera y el proceso de transformación de los campesinos dedicados al autoabastecimiento en productores de palma africana. Finalmente, caracterizaré el proceso de venta de las tierras de la cooperativa desde la perspectiva de Eugenia, para explorar cómo fueron “domesticadas” las dinámicas del despojo y cómo transformaron las relaciones entre hombres y mujeres en el proceso.

\section{El Bajo Aguán}

Lo que se conoce como el Bajo Aguán, la parte baja de la cuenca del río del mismo nombre, es un valle de tierras aluviales muy fértiles que se extienden por más de 200.000 ha (Jones 1985). Tradicionalmente fue visto como un espacio "vacío”, pero en la década de los veinte y los treinta los ojos del Estado hondureño se fijaron en la región cuando grandes extensiones de tierra se entregaron a la Truxillo Railroad Company — subsidiaria de la United Fruit Company_- para el cultivo de banano. A finales de 1940, como resultado de la proliferación del mal de Panamá (Fusarium oxysporum), un hongo que ataca las raíces de ciertas variedades de banano, la empresa abandonó la región del Bajo Aguán (Soluri 2009) dejando detrás un conjunto de pequeños asentamientos de extrabajadores de la bananera y el ferrocarril, así como de inmigrantes salvadoreños y comunidades garífunas ${ }^{3}$ (Casolo 2009). Para las décadas de los sesenta y setenta, la región se convirtió en la casa del Proyecto Bajo Aguán, una iniciativa de colonización inducida y pieza central de la reforma agraria hondureña. Es en este contexto que la historia de la región se conecta con las vidas de Eugenia y Martino. 


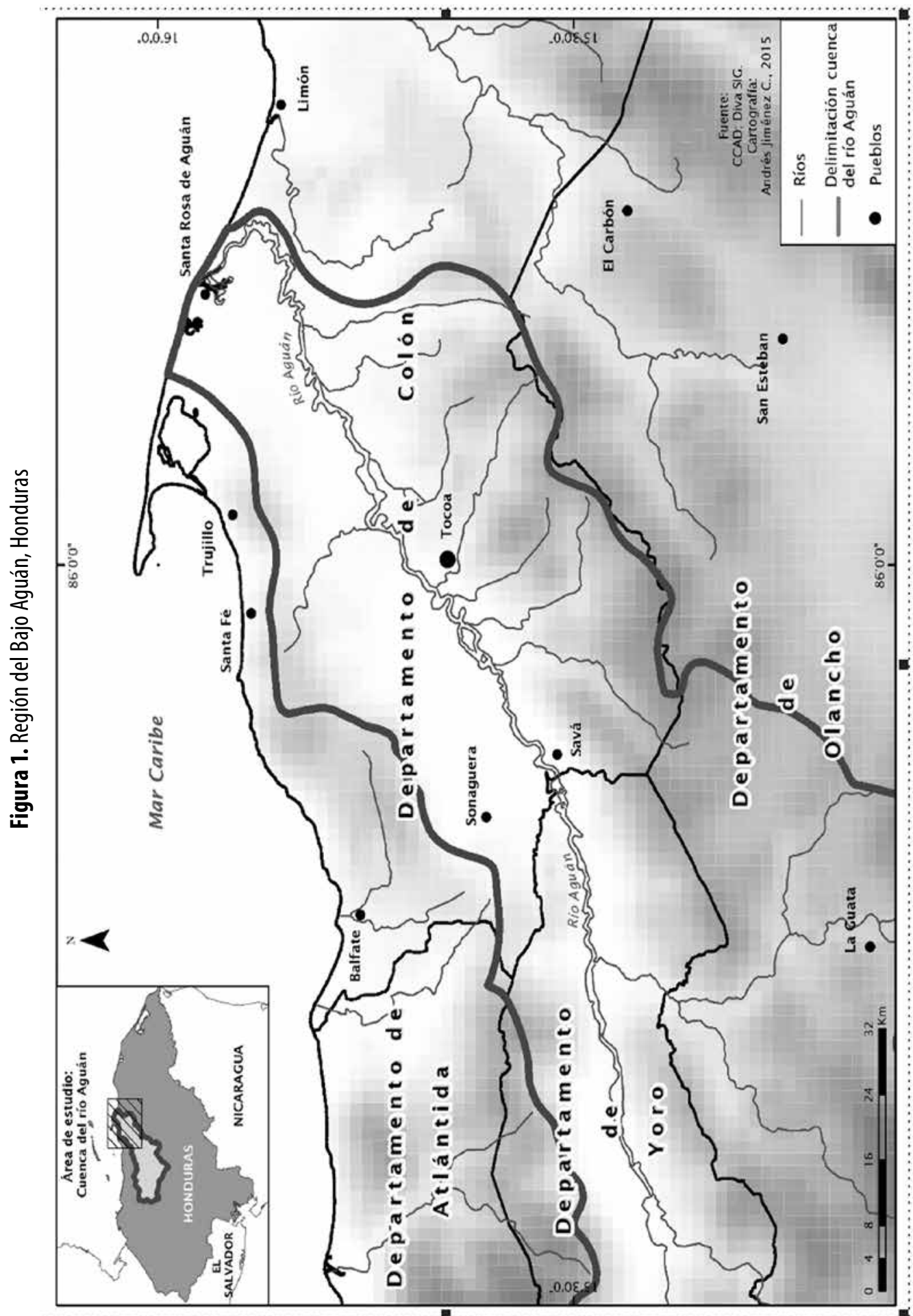

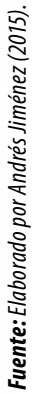




\section{Ensamblar el despojo: de Copán al Bajo Aguán}

En Centroamérica, las décadas de los sesenta y setenta están marcadas por una ascendente conflictividad agraria vinculada, sobre todo, a la creciente penetración de las relaciones capitalistas de producción en el campo y al tipo de articulación con el mercado global, todavía dominado por el enclave bananero pero combinado con un esfuerzo de diversificación productiva alrededor de actividades como el algodón y el azúcar (Bulmer-Thomas 2003; Williams 1994). Para este periodo, Honduras se encontraba fragmentada en tres grandes zonas. En la costa norte, el enclave bananero continuaba operando como un imán para la población migrante de las diferentes partes del país. Sin embargo, tras la gran huelga de $1954^{4}$, las transnacionales habían despedido a más de la mitad de su fuerza de trabajo (alrededor de 13.000 personas), lo que generó una proliferación de ocupaciones de tierra e incentivó la migración informal hacia las tierras “vacías” de la zona oriental del país (Soluri 2009).

En la zona por fuera de la influencia del enclave bananero, hacia el sur del país, la acelerada proletarización y el despojo de tierras llevó a que una élite ganadera controlara la mayor parte de las tierras y el trabajo, lo cual incentivó la expansión de las industrias ganadera, azucarera y algodonera y dejó como saldo un creciente número de conflictos entre terratenientes y campesinos (Boyer 1982; Williams 1986). En el oeste, en las tierras donde nacieron Eugenia y Martino y con un fuerte componente indígena lenca, se mantenía una economía basada en pequeñas fincas productoras de milpa ${ }^{5}$ y café, con niveles de producción cada vez más bajos, debido a la erosión, al acaparamiento de tierra por terratenientes y al influjo de migrantes campesinos pobres y familias indígenas chortis desde Guatemala y El Salvador (Anderson 1983; Metz 2010).

Cuando le pregunto a Eugenia y Martino sobre su vida antes de migrar al Aguán, Eugenia me responde: “Bueno, en Copán era trabajar en el jornal...”. “Allá solo día trabajado, día comido...”, agrega Martino. Ella continúa:

Y sin tierras, no teníamos tierras. Él andaba alquilando dónde trabajar, dónde hacer su pedacito de milpa. Pues yo como mujer solo atendía a

$4 \quad$ En mayo de 1954, más de 25.000 trabajadores bananeros se fueron a huelga en búsqueda de mejores condiciones laborales y salariales y del derecho a sindicalizarse. La huelga duró más de dos meses y es entendida como una de las más grandes victorias del movimiento obrero hondureño (Barahona 2005; Euraque 2001).

5 La milpa es la siembra mediante tala, roza y quema de fríjoles, maíz y chayote (Sechium edule) en el mismo terreno. Véase Lara Ponce, Caso Barrera y Aliphat Fernández (2012). 
los niños, teníamos dos niños, verdad, en Copán teníamos una niña. Y después migramos para Atlántida...

La ausencia de tierra, la necesidad de Martino de trabajar como jornalero y el hecho de que Eugenia se tuviera que quedar cuidando a los hijos deben entenderse en un contexto más amplio de penetración de las relaciones capitalistas en el campo, de transformación de las unidades domésticas y, por tanto, de las relaciones entre hombres y mujeres ${ }^{6}$.

Existe un consenso dentro de la literatura antropológica de que en las organizaciones sociales corporativas, tales como las comunidades campesinas e indígenas, las redes de parentesco son fundamentales para la organización y reproducción social (Fox 2004; Robichaux 2008; Wolf 1971, 1980). Dentro de lo que se conoce como el sistema de parentesco mesoamericano (Robichaux 2005), dichas redes están conformadas por relaciones basadas en sangre y matrimonio, pero también en lazos de amistad, lugar de origen e instituciones y rituales sociales como el compadrazgo. No todas estas relaciones tienen la misma importancia; en el centro suele estar la familia nuclear, en la cual es fundamental la relación entre hermanos y hermanas. Otras formas de vinculación - como la amistad y el compadrazgo - se organizan alrededor de este núcleo y se vuelven particularmente importantes en situaciones de migración, donde las personas tienden a seguir las rutas por las que anduvieron otros (Arizpe 1980; Massey et al. 1999; Moctezuma Pérez 2006).

De manera general, esquemática y fundamentada en lo que nos dice la literatura secundaria (especialmente, Chapman 1985; Robichaux 2005; Roquas 2002), podemos describir el momento de la penetración de las relaciones capitalistas en el campo a partir de la década de los sesenta, como aquel en el que, si bien existían relaciones de mercantilización y explotación del trabajo, estas ocurrían en una escala fundamentalmente comunitaria, y cuando mucho regional. Lo que prevalecía era, más que relaciones salariales, formas de peonaje y alquiler de tierras, y el idioma del parentesco era el mecanismo fundamental de control y dominación. Es decir, las formas mediante las cuales los terratenientes reproducían su posición de mando y controlaban el trabajo de los grupos subalternos eran un complejo sistema de instituciones formales e informales que incluían relaciones contractuales, conjuntos de obligaciones determinadas por relaciones de parentesco

6 Esta interrelación entre transformaciones en las relaciones de producción y las dinámicas dentro de la unidades domésticas es lo que denomino domesticación, siguiendo a Judith Carney y Michael Watts (1990). Más adelante aclararé cómo se entiende en este contexto específico. 
(por ejemplo, el compadrazgo [Mintz y Wolf 1950]) y un arraigado "sentido común”" que naturalizaba dichas relaciones de mando (Roux 2005; Yie 2015).

En términos de producción, la mayoría de las unidades familiares se dedicaba a una agricultura de autoabastecimiento caracterizada por el cultivo de la milpa y la cría de especies menores como gallinas y cerdos. La producción manufacturera era limitada y estaba supeditada al espacio comunitario, por lo que circulaba poco dinero y la mayor parte del trabajo, agrícola o doméstico, no era remunerado monetariamente. El trabajo se organizaba según el género: las tareas agrícolas, como la chapea o la siembra, se entendían como "trabajo de hombres”, mientras que el trabajo doméstico - cocinar, recoger agua, lavar la ropa, cuidar a los hijos, entre otros - era, y es, visto como “trabajo de mujeres”. Dicha división del trabajo se extendía generacionalmente, ya que los hijos tenían que trabajar desde niños y obedecer a sus padres. El trabajo colectivo comunitario también era fundamental, en particular, en las comunidades de descendencia lenca en el occidente del país; allí las personas unidas por lazos de parentesco trabajaban en las tierras de los demás en condiciones altamente ritualizadas y centrales para la reproducción identitaria de las comunidades (Chapman 1985).

Finalmente, el acceso a la tierra estaba organizado tanto alrededor de las redes de parentesco ${ }^{8}$ como de la constante expansión de la frontera agrícola, basada en la idea del acceso libre a la tierra o de una frontera agraria abierta. Esto queda evidenciado en la institución de herencia presente en las comunidades lenca conocida como el lazuro. En este sistema, la tierra era heredada en su totalidad al hijo menor (el lazuro) y así no se fragmentaba. Pero el sistema además tenía como corolario que, al casarse, los hijos mayores podían acceder a tierra libre en otra parte y el hijo menor sería el encargado de cuidar a los padres. En el caso de las mujeres, su acceso a la tierra era indirecto y a través de sus esposos, por lo que quedaban excluidas de la herencia (Roquas 2002). Podemos ver entonces que la migración estaba profundamente arraigada en el sistema de acceso a la tierra y reproducción de las comunidades mismas.

Con la mayor penetración de las relaciones capitalistas, este sistema empezó a cambiar. Primero que todo, la diversificación de la estructura productiva

7 Entiendo por sentido común el conjunto de supuestos incoherentes y contradictorios que no son cuestionados y que son absorbidos de manera acrítica, del contexto social y cultural en el que son criadas personas específicas. Desde esta perspectiva, no existe tal cosa como un sentido común homogéneo, sino que responde al contexto histórico y de clase en el que crecen las personas (Crehan 2002; Gramsci 1999).

8 Es importante aclarar que mi intención acá no es dar una definición detallada del sistema de parentesco hondureño. Mi objetivo más bien es enfocarme en la manera como dichas relaciones de parentesco operaban, según la definición de densas redes y nodos de relaciones sociales que atan a personas de diferentes edades y formas de filiación (Bourdieu 2008). 
y los usos nuevos y más intensos de la tierra, por parte de las industrias ganadera, algodonera, azucarera y cafetalera, vinieron acompañados por procesos más agresivos de despojo (sobre todo mediante la expropiación directa por medios legales y extralegales), cercamiento (desaparición de las tierras comunales y baldíos ${ }^{9}$ y concentración de la tierra en manos de las élites (Boyer 1982; Edelman y León 2014). Esto a su vez "liberó" a una gran cantidad de personas de la tierra, lo que intensificó y expandió los circuitos de migración campesina y empezó a poner mucha presión en sistemas sociales como el lazuro. El que ya no hubiera tierras accesibles significó que los hijos mayores no pudieran irse de la casa tan fácilmente, lo que eventualmente llevó a la configuración de un sistema hereditario en el que las tierras paternas eran repartidas entre los hijos, con lo cual se fragmentó aún más la tierra y se generaron nuevos conflictos en términos de propiedad (Roquas 2002).

Así, para los sesenta, nos encontramos con una situación de fragmentación fundiaria y concentración de la tierra por parte de las élites. Como resultado, el abastecimiento de las familias provenía cada vez menos de su propia producción —-debido a la reducción de las propiedades y la pérdida de fertilidad a causa de años de agricultura de roza y quema-y de la necesidad de destinar mayor parte de la producción para el mercado, a fin de acceder a fondos monetarios para asegurar el abastecimiento familiar. Esta situación implicó que una mayor parte de la población buscara trabajo asalariado lejos de la parcela, y de la comunidad en muchos casos, para complementar la producción doméstica, lo que a su vez se tradujo en que las mujeres empezaran a trabajar más en las parcelas. Los padres también se vieron obligados a intentar mantener a los hijos varones dentro de la unidad doméstica para que trabajaran, ya fuera en las tierras familiares o como trabajadores asalariados, para traer ingresos monetarios.

En un proceso similar al descrito por Simmel $(1978)^{10}$, la monetarización conllevó una corrosión de las instituciones tradicionales como el lazuro y el trabajo colectivo comunitario. También, y como veremos más adelante, la

9 Es importante mencionar que, como en el resto de Centroamérica, el proceso de desaparición de las tierras comunales y baldíos se inició desde finales del siglo XIX con las reformas liberales. Sin embargo, por distintas razones que superan los intereses del presente artículo, para la década de los cincuenta y sesenta existía aún una significativa cantidad de tierras en manos de las comunidades campesinas y las municipalidades (Cáceres y Zelaya 2005; Edelman y León 2014). El ciclo de despojo mencionado aquí se refiere sobre todo a la alienación y concentración de estas tierras (véase Boyer 1982, para una caracterización de estos procesos en el sur del país). disolver los elementos personales de las relaciones entre individuos. Es decir, mediante el intercambio monetario, se despliega un orden de funciones separadas de las personalidades, y este orden se objetiva frente a la personalidad como algo exterior a ella. 
introducción del dinero en el abastecimiento de la unidad familiar ocasionó un cambio en las relaciones entre hombres y mujeres y con respecto a la unidad doméstica, fundamentalmente en la perniciosa separación entre producción y reproducción, dos esferas que pasaron a ser entendidas como completamente separadas $^{11}$ (Federici 2004).

El caso de Eugenia y Martino ilustra esta situación de forma concreta. Históricamente, cuando una pareja joven como ellos decidía empezar una familia, pasaban un periodo inicial en las tierras del padre del hombre y luego migraban en búsqueda de tierras. En este caso, después de un tiempo “arrimados” en la casa del papá de Martino y ante la imposibilidad de conseguir buenas tierras cerca debido a los procesos antes descritos, tomaron la nada fácil decisión de migrar fuera de la región, hacia Atlántida, en la costa norte del país y dentro de la esfera de influencia del enclave bananero. Esta decisión debe ser entendida en un campo social marcado tanto por la desintegración de las instituciones tradicionales, como por el doloroso e incierto parto de nuevas formas de entenderse en tanto unidad doméstica, en proceso de ruptura con instituciones tradicionales como el lazuro y la necesidad de migrar fuera de las tierras natales. En términos más generales, marca un contexto en donde el despojo y la concentración de las tierras antes mencionados obligaban a las familias a escoger entre tres opciones: 1) quedarse y ser capturados por las nuevas relaciones de producción capitalistas — como lo ilustra la condición de jornalero de Martino-; 2) organizarse políticamente en alguna de las centrales campesinas que se empiezan a activar en este periodo y luchar por la tierra mediante recuperaciones, o 3) migrar en busca de una mejor situación, es decir, huir de las relaciones de despojo y captura capitalista.

Después de haber salido de Copán, su comunidad de nacimiento, Eugenia y Martino llegaron al municipio de Esparta donde construyeron una champita - un rancho con techo de palma y paredes de barro- al lado de un río. Allí nacieron otros dos niños y la familia creció. Ellos no me cuentan mucho de este periodo, pero al parecer la vida no era necesariamente más fácil que cuando se encontraban en Copán. Es importante apuntar que, aunque Esparta se ubica cerca de las plantaciones bananeras, Martino nunca trabajó ahí como jornalero. A este punto volveré luego.

El 18 de septiembre de 1974, el huracán Fifí azotó de manera particularmente severa la costa norte hondureña, y dejó detrás de sí una estela de

11 Esto no quiere decir que en el periodo anterior las mujeres no se encontraran en una situación de subordinación y dominación, pues las dinámicas patriarcales preceden a las relaciones capitalistas. Sin embargo, existe un acople pernicioso entre el capital y las relaciones patriarcales que tiende a invisibilizar y naturalizar estas formas de subordinación mediante el mercado y la supuesta separación entre la producción y la reproducción. 
destrucción que tampoco perdonó a la familia de Eugenia. El río Lean, junto al cual habían construido su champita, creció de manera significativa, destruyó su casa y mató a los pocos animales que tenían. Como dice Martino, los dejó “con los brazos cruzados”, sin trabajo ni un lugar donde vivir. En el periodo posterior al huracán, las centrales campesinas hondureñas estuvieron muy activas organizando a las familias damnificadas y, en colaboración con el Gobierno militar ${ }^{12}$, las trasladaron a la región del Bajo Aguán dentro del proyecto de colonización dirigida que se estaba llevando a cabo en este lugar (Castro 1994). Sin ninguna otra opción viable, Martino, Eugenia y otros miembros de la familia que los habían seguido a Atlántida pronto colocaron las pocas pertenencias que tenían en un camión que los llevaría hacia el Valle del Aguán a formar parte de una de las cooperativas que se estaban creando con la reforma agraria.

Para entender esta situación debemos detenernos por un momento e incluir algunos elementos. Como ya mencioné, las décadas de los sesenta y setenta habían sido de mucha tensión social en el campo hondureño. La gran huelga bananera de 1954 — denominada por Ramón Amaya Amador (1988) como la "Comuna de Honduras”- había inaugurado dos procesos paralelos que transformaron las zonas rurales del país. Por un lado, se presentó un aumento en los niveles de organización y combatividad del campesinado. Por el otro, hubo un creciente involucramiento de los mandos militares en el Gobierno, particularmente después de la guerra con El Salvador en 1969, el golpe de Estado de 1964 y el posterior ascenso a la silla presidencial del general Oswaldo López Arellano en 1972, tras otro golpe militar (Barahona 2005; Euraque 2001). El resultado fue un acercamiento a la planeación desde una perspectiva "desarrollista”, de modo que el Estado debía desempeñar el papel dual de potenciador de la actualización histórica de la sociedad, como lo planteó el Plan Nacional de Desarrollo de 1972, y como mediador y apaciguador de la lucha de clase. En ningún lugar era más clara esta articulación que en el acercamiento y la centralidad que tendría la cuestión agraria para el régimen militar.

En 1960 - un año antes de la famosa Conferencia de Punta del Este en la que se inaugurara la Alianza para el Progreso-, el Gobierno hondureño solicitó apoyo a la Organización de Estados Americanos (OEA) para poner en marcha una política de desarrollo agrario que fuera mucho más allá de una simple reforma agraria y que permitiera articular el desarrollo agrario con el industrial. A finales de 1960, la OEA respondió con la creación de la llamada Misión 105, compuesta por distintos especialistas. Debido a la ausencia de la información técnica 
necesaria, se concentró en el diseño de dos proyectos de colonización: uno en la zona sur del país y el otro en la cuenca del río Aguán (OEA 1964).

Conocido como el proyecto Bajo Aguán ${ }^{13}$, al principio era sumamente ambicioso e iba mucho más allá de la distribución de tierra. Con el argumento de que el valle del Aguán tenía un gran potencial productivo, pero que se encontraba "vacío", lo que irónicamente desmiente el mismo informe del proyecto (OEA 1964), se proponía la selección de familias de diferentes partes del país donde había conflictos por la tierra (más de 6.000 familias), basada en varias escalas sociológicas y físicas, para llevarlas al Aguán. Allí desarrollarían más de 70.000 hectáreas en proyectos productivos dirigidos al mercado, sobre todo de cítricos y palma africana. La necesidad de que produjeran para el mercado estaba dirigida a "recuperar" la inversión estatal en la compra de las tierras y su preparación (infraestructura), así como a transferir una buena parte de la deuda adquirida con los organismos internacionales a las familias campesinas. Recordemos que existen muy pocos casos en los que las tierras de reforma agraria no hayan sido "vendidas" a las familias campesinas beneficiadas (Courville, Patel y Rosset 2006; Thiesenhusen 1995).

Dicho en otras palabras, se proponía aprovechar el potencial productivo del Bajo Aguán en dos direcciones. Por un lado, llevar campesinos de otras zonas conflictivas en el país serviría para desactivar el conflicto agrario en términos nacionales. Por el otro, al convertir a estos campesinos, caracterizados como de "subsistencia”, en productores para el mercado, se lograría desarrollar económicamente el país. En el caso específico de la palma africana, la idea era aún más ambiciosa: con el desarrollo de este cultivo se podría también desarrollar la industria. Es decir, el proyecto Bajo Aguán era presentado como la llave maestra del desarrollo hondureño. Inicialmente, se suponía que arrancaría en 1969, sin embargo, debido a eventos como la llamada "guerra del fútbol" (Kapuscinski 1992) entre El Salvador y Honduras en 1969, y a la ausencia de un marco legal agrario que definiera la forma de distribución de la tierra, el proyecto - financiado en un $60 \%$ por la OEA, por un total de 13 millones de dólares) - se atrasó hasta 1971. Este proyecto solo tomó fuerza después del huracán Fifí, cuando la política agraria del Gobierno militar se aceleró de manera significativa. 


\section{La llegada al Bajo Aguán: de milperos a palmeros}

Cuando Eugenia y Martino aceptaron organizarse con la central campesina y movilizarse al Aguán, lo hicieron con la idea de que tendrían una casa donde vivir, tierra lista para trabajar y las condiciones de vida básicas. La realidad estaba lejos de estas promesas. El camión que los había recogido en Atlántida los dejó en unas tierras en la margen izquierda del río Aguán, en una comunidad conocida como El Monte ${ }^{14}$, donde se incorporaron inmediatamente a la cooperativa del mismo nombre. A diferencia de lo que les habían dicho, la tierra estaba cubierta en guaimil —bosque cerrado con mucha maleza-y además se veían obligados a alimentarse con las ayudas humanitarias que los organismos internacionales le donaban a Honduras. Eugenia lo recuerda como un periodo difícil:

Cuando llegamos veníamos con las dos niñas, venimos a comer un maíz todo podrido, nos daban un pescado podrido, nos daban una avena mojada, húmeda, que tenía mal olor y la teníamos que comer porque no había más que comer... Por él, por la tierra fue que nos venimos. Entonces cuando empezamos a ver y yo empiezo a ver que no hay agua ahí fue yo me sentía incómoda, púchica, mejor vámonos de aquí. "No, me decía, que ya fuimos a ver las tierras, vieras qué buenas tierras, y aquí vamos a hacer milpa y mira y bueno...”. Y mi mamá, que me apoyaba, también me decía: "No, hija, para superar hay que sufrir, mira que aquí no hay agua pero mira vamos a ver cómo hacemos...”. Hicimos champas de zinc, nos prestaron champas de zinc, ahí cocinábamos y sacábamos agua de unos pozos que estaban profundos con galones. Y la mayoría peleando el poquito de agua, porque la gente quería agua... Entonces ya de ahí tomábamos agua. Y esa agua cuando nosotros llegábamos otro día, como no la tapábamos no se nos venía a tapar ese pozo... Pero ranas, sapos, todo caían adentro... ¡Ay, eso es terrible! Yo ni acordarme quisiera, pero bueno, ojalá no llore, verdad (risas). Fue en esto que estuvimos allí, pues, y ya ellos trabajando.

Como podemos ver, el traslado al Aguán en vez de una mejoría les trajo aún más dificultades y trabajo duro. Son interesantes las razones por las cuales se movieron: Martino seguía en la búsqueda de una buena tierra a la que pudiera llamar suya. Al mismo tiempo, para Eugenia el tema más bien se inscribía en lo que Raquel Gutiérrez (2015) denomina el horizonte comunitario-popular, 
es decir, aquellas lógicas de lo común ${ }^{15}$ que, en tiempos cotidianos y ordinarios, “[...] se despliegan a partir de fines centrados en la conservación y cuidado de los recursos materiales colectivamente disponibles, colocando como eje la garantía de condiciones materiales para la reproducción de la vida colectiva” (123). Encontré constantemente esta diferenciación en los testimonios de las mujeres y los hombres que migraron hacia el Aguán. Los hombres, en la mayoría de los casos, narraban el trayecto como una búsqueda incesante - siempre incompleta y algo trágica - de un pedazo de tierra propio y de la autonomía para trabajarla libremente, sin "darle el pulmón a otro”, como se refieren a trabajar para que otra persona disfrute de su sudor. Esto a su vez se veía reflejado en diferentes temporalidades: mientras que los hombres recuerdan desde sus esperanzas y anhelos, siempre en un futuro nunca alcanzado, las narraciones de las mujeres tienden a concentrarse en los procesos más cotidianos e inmediatos. Por ejemplo, mientras que los hombres empezaban a trabajar en el desmonte y la siembra de la milpa, las mujeres se concentraban, además del trabajo doméstico, en agenciar otras fuentes de alimentación para sus familias. Eugenia menciona:

Ah, qué poco de tomates, mire, nosotros que hallábamos qué comer ahí íbamos a cortar los poquitos y los asábamos en la plancha y así le dábamos comida a las niñas, fue terrible, terrible... Pues cuando ya vi el lote, ya parece que la vida cambió, ya comíamos maíz bueno, ya yo atendía a una gallina, ya ponía un huevito, ya íbamos, ya cambió, la diferencia...

Sin embargo, esta mejoría no duraría, ya que a los pocos años de haberse ubicado en El Monte, a finales de los setenta,

[...] viene el proyecto de palma y le meten las buldozas [buldóceres] al maíz, no esperan ni para cosechar este maíz. No, es que había bastante debilidad de cerebro. Y yo decía: “iAy no!, mujeres, miren cómo están botando esas milpas. ¿Por qué están botando esas milpas? ¿Por qué no las cosecharon?”. “No, porque ya este proyecto ya tiene que ser, es que este proyecto ya tiene que ser...”.

La introducción de la palma africana al Aguán merece un tratamiento más detallado y profundo que no le puedo dar en este momento, por lo que simplemente mencionaré algunos aspectos. Este cultivo nativo de África llegó a Centroamérica en los años treinta, de la mano de las transnacionales bananeras que lo introdujeron en Honduras como una posible alternativa al monocultivo

15 En términos generales utilizo la definición de lo común propuesta por George Caffentzis y Silvia Federici (2013): "los comunes anticapitalistas son mejor entendidos como espacios autónomos desde los que podemos reclamar el control sobre nuestras vidas y las condiciones de nuestra reproducción, así como proveer recursos basados en el compartir y el acceso equitativo" (92). 
bananero que se veía atacado por varias enfermedades, como el mal de Panamá. Tras varios años de pruebas, después de quedar demostrada la factibilidad industrial del cultivo en el istmo, en la década de los sesenta se empezaron a desarrollar plantaciones en diferentes partes (Quepos en Costa Rica, por ejemplo); y, curiosamente, el Banco Mundial empezó a financiar proyectos de producción palmera por parte de campesinos organizados en diferentes partes del mundo, como Malasia y Costa Rica, entre otros (Clare 2011; Kerssen 2013; Robertson 1984).

Si bien la industria palmera cuenta con características comunes, la forma en que se puede producir y cómo se produce cambian dependiendo del contexto específico en el que se desarrolla. Para simplificar la discusión, podemos hablar de dos formas dominantes de organización de la producción palmera. Por un lado, se encuentran las extensas plantaciones de palma africana en manos de grandes capitales, que además integran verticalmente toda la cadena productiva (producción, transformación, comercialización) y contratan mano de obra dependiendo de los ciclos del cultivo. Por el otro, hay asociaciones de pequeños productores y cooperativas campesinas que manejan la tierra de manera conjunta o dividida, utilizan fuerza de trabajo familiar, con contrataciones de mano de obra extra para ciertos periodos del proceso productivo, y venden la materia prima a plantas procesadoras privadas o de propiedad colectiva (cooperativas de segundo nivel, por ejemplo). Por lo general, lo que encontramos es una combinación de ambos modos de producción en los distintos territorios palmeros, con diferentes niveles de interacción y conflictividad entre ellas. Es importante tener en cuenta este contraste cuando se piensa en las formas que toma el sector palmero en distintos países y regiones específicas. Sin embargo, sea en asociaciones, cooperativas o grandes empresas transnacionales, la producción palmera requiere una sustantiva inversión inicial de capital (preparación de las tierras, compra de semillas, infraestructura, entre otros), una gran cantidad de hectáreas dedicadas al cultivo cercanas a las plantas extractoras y, debido a que es una actividad intensiva en mano de obra, un régimen laboral que permita mantener una fuerza de trabajo relativamente barata y cautiva (esto es, "amarrada” al lugar).

En el caso de las formas asociativas, su desarrollo histórico ha sido el resultado de un esfuerzo y empuje estatal combinado con fuentes de financiamiento aportadas por instituciones financieras como el Banco Mundial y el Banco Interamericano de Desarrollo (BID). Quizá el ejemplo más famoso de esta forma de producción palmera es aquel impulsado por la Autoridad de Desarrollo de Tierras Federales (Felda, por sus siglas en inglés) de Malasia, y que controla alrededor de un tercio de la tierra dedicada a la palma africana en dicho país del Sudeste Asiático (Corley y Tinker 2008; Robertson 1984). Otro caso es el del sector palmero 
hondureño que se creó en el marco de la reforma agraria (De Fontenay 1999; Kerssen 2013). Desde que se empezaron a organizar las primeras cooperativas en 1971, el Instituto Nacional Agrario (INA) intentó introducir la producción de palma. No obstante, una y otra vez se encontró con la negativa de un campesinado acostumbrado a la producción de maíz y fríjol y sin ningún conocimiento de la palma africana. Su consolidación definitiva se dio en 1974, después de que el huracán Fifí destruyó la mayor parte de las milpas sembradas por las cooperativas, que de un día al otro se vieron altamente endeudadas e "invitadas" a producir palma como única forma de generar suficientes ganancias para pagar lo que debían de las tierras que les habían otorgado. En otras palabras, la deuda mezclada de forma explosiva con un evento natural como el huracán tuvo como resultado la generación de vulnerabilidades y subordinación (Smith 2006; Watts 2013).

Es importante subrayar que esta transición fue bastante compleja y dolorosa. Primero que todo, al tratarse de un cultivo poco conocido por los cooperativistas, quienes lo sentían como una imposición externa, la palma africana no fue bien recibida inicialmente. Como me contaba un miembro de una de las cooperativas, aunque en ese momento había un profundo sentido entre los cooperativistas de que las tierras eran suyas, se decía que "las palmas eran del BID”16. Pero también, y de manera más importante, el ingreso a las cooperativas, y particularmente la organización productiva de la palma africana, se tradujo en un profundo proceso de disciplinamiento (Carney y Watts 1991; Thompson 1967) para las familias campesinas. Como lo mencioné, la travesía de muchas de estas familias hacia el Aguán se veía propulsada por un sentimiento de autonomía bastante individual entre los hombres — no darle el pulmón a otro-y su búsqueda incesante de un pedazo de tierra propio en el cual producir para autoabastecerse. En las cooperativas la lógica era distinta. Allí la producción para el autoabastecimiento quedaba supeditada a la producción para el mercado, que era la única forma de generar las suficientes ganancias para pagar deudas y asegurar el abastecimiento de las familias. Es decir, las familias, y particularmente los hombres, delegaban el poder de decidir sobre lo que se producía y cómo se producía a la junta directiva de la cooperativa, que a su vez debía responder a los designios e instrucciones de las instituciones externas.

Aunque las familias no se morían de hambre, la situación en las cooperativas estaba bastante lejos de la opulencia. Debido a que la palma africana empieza a producir a los tres o cuatro años de sembrada y llega al pico de producción después de diez años, el abastecimiento de las familias se conseguía 
parcialmente de lo que sembraban en combinación con las palmeras - al menos hasta que estas crecían tanto que se volvía imposible cultivar, o como en el caso de El Monte, hasta que las milpas eran desplazadas por más palmeras-, o por un supuesto adelanto que les daba el INA de las futuras ganancias de las cooperativas. En la práctica, este ingreso era entendido y funcionaba como un salario de hambre que los convertía prácticamente en jornaleros en sus propias tierras.

El desplazamiento de las milpas por más palmeras tiene que entenderse dentro de un marco de transformación más amplio, en lo que respecta al abastecimiento de las familias campesinas pertenecientes a las cooperativas. Si, de acuerdo con la lógica de las unidades domésticas individuales que se replicó inicialmente en las cooperativas, la idea era que buena parte del abastecimiento proviniera de la propia producción de granos básicos, con la palma pasó a conseguirse por medios monetarios debido a la lógica del monocultivo y a que el bienestar solo se consigue después de la venta en el mercado. Si a esto le sumamos la necesidad de las cooperativas de pagar sus deudas, es evidente que con esta nueva lógica de "más es mejor” se abrió la puerta al reino de los monocultivos, mientras que el maíz y los fríjoles, que podían ser comprados, pasaron a un segundo plano en las prioridades de la organización.

\section{Eugenia, las vacas y las palmeras: una tragedia a tres golpes}

Para explorar el tipo de impacto que tuvo el paso al monocultivo palmero tanto en el interior de las unidades domésticas, y por tanto entre hombres y mujeres, como en el contexto del Aguán en términos más generales, vale la pena observarlo en relación con el proceso de contrarreforma agraria (Macías 2001) que se llevó a cabo en Honduras a principios de 1990. En 1992, y como parte del ajuste estructural en el país, se aprobó la Ley para la Modernización y Desarrollo del Sector Agrícola que, si bien no eliminó la normativa de reforma agraria, sí levantó las restricciones para la venta de tierras distribuidas en el marco de esta. El resultado fue que para 1994, dos años después de su aprobación, más de un 50\% de las tierras distribuidas entre 1972 y 1992 fueron alienadas y, cuando pasamos al Aguán, este número subió a un 70\%. En este caso las tierras fueron concentradas por dos terratenientes y una transnacional: Miguel Facussé (34\%), Reynaldo Morales (23\%) y la Standard Fruit Co. (8\%), respectivamente. Es importante aclarar que, aunque este proceso de alienación no siempre fue sangriento, sí estuvo 
marcado por altos niveles de violencia ${ }^{17}$ y coerción, incluyendo el asesinato de muchos líderes campesinos que se negaron a vender las tierras.

Como mencioné, dicho proceso comúnmente se analiza desde una perspectiva masculina y una racionalidad económica, en la cual las cooperativas que no fueron forzadas a entregar sus tierras, bien por amenazas, asesinatos o triquiñuelas legales, vendieron las fincas por dos razones. En primer lugar, debido a la corrupción de los dirigentes que habían hecho de las cooperativas empresas poco exitosas, al poco apoyo del Gobierno y a la extrema pobreza en la que vivían las familias, lo cual hacía que ganarse el equivalente de unos 500 dólares por la venta no fuera tan mal negocio. En segundo lugar, a causa de la falta de apropiación de las tierras por parte de los miembros. En contraposición a esta narrativa, Eugenia cuenta una historia de la contrarreforma agraria que se empieza a gestar con la siembra misma de las palmeras hacia finales de los setenta. Con lo que podríamos denominar tres golpes, ella me describe cómo al mismo tiempo en que las mujeres fueron separadas de las actividades productivas/remuneradas de la cooperativa, se iban preparando las condiciones de posibilidad para la posterior venta de las tierras. En el primer golpe, el lugar de habitación de las familias fue separado del lugar de siembra de las palmeras; en el segundo, perdieron las vacas; y el tercero correspondió a la pérdida de las tierras.

Con respecto al primer golpe, cuando Martino y Eugenia llegaron al Aguán no había diferencia entre sus espacios domésticos y la milpa o, posteriormente, el monocultivo palmero. Estas eran tierras bajas, cercanas al río Aguán y, por lo tanto, vulnerables a inundaciones. Por esta razón, hacia mediados de 1980 la junta directiva de la cooperativa les informó que ya no podían vivir más ahí y que, con apoyo del Estado, se estaba desarrollando un proyecto domiciliario en unas tierras más altas y seguras. Sin embargo, en retrospectiva, para Eugenia esta no fue una decisión tan inocente.

Hoy me doy cuenta, [...] con razón decían los directivos: “Miren, aquí no podemos quedarnos... Pero era tiempal que habíamos vivido allí, pues, si allá yo parí a todos mis hijos, llegué solo con dos chigüines y de allí parí a todos mis hijos, allí abajo...”. Bueno y decían: “Bueno, ya no vamos a vivir aquí porque esas llenas nos pueden arrastrar, mejor hay que irnos para Ocotes Altos, allá arriba, decían, hay que comprar e irnos para allá”. Entonces vinieron y agarraron un pedazo ahí y repartieron

17 En este contexto entiendo la violencia en la línea planteada por Ignacio Martín-Baró (1972): "[v]iolencia no es lo mismo que sangre, aunque muchas veces la sangre acompañe a la violencia. Violencia quiere decir ruptura, y la ruptura es [...] con una manera de ser social, política [concreta]. La violencia apunta a un abismo de discontinuidad entre el sistema existente y aquel que se pretende instaurar" (172). 
los solares, lo que es La Colonia, El Monte, todas para allá... Y, entonces, ya nosotros compramos aparte el solarcito para venirnos para acá.

Para ella esta separación representaba dos cosas: primero, que eventualmente sería más fácil vender las tierras si nadie estaba viviendo ahí; segundo, separaba literalmente los espacios de trabajo doméstico de los de trabajo agrícola y, por tanto, los marcaba en términos de género, reflejando lo que históricamente ha sido la perniciosa división entre las esferas de producción (las palmeras) y reproducción (casas de habitación) (Federici 2004). Así, el paso hacia el monocultivo palmero y la subsiguiente dependencia del mercado para el abastecimiento de las unidades domésticas hacía que las mujeres fueran más dependientes de sus parejas y que su trabajo doméstico se volviera aún más invisible. Con la separación de los espacios fue más difícil para las mujeres saber cuánto les pagaban a sus esposos por semana, ya que el pago se hacía en "las palmeras”, ahora separadas de sus casas de habitación, y por tanto tener algún tipo de fiscalización sobre esos fondos.

Pero dicha reubicación también tuvo un efecto en términos del uso de la tierra por parte de las mujeres. Antes del proyecto de vivienda había pocas diferencias entre los espacios de cada familia, por lo que las mujeres pasaban más tiempo juntas cuidando el ganado, plantando algunas hortalizas, recogiendo madera, cuidando a los niños y lavando. Una vez que pasaron a las nuevas casas, el terreno de cada familia estaba separado de las demás con cercas y tenía su propio pozo de agua, lo que rompía los espacios colectivos y debilitaba las formas de solidaridad femenina profundizando aún más la separación entre espacios públicos (fundamentalmente masculinos) y privados (predominantemente femeninos).

Después vino la venta de las vacas. Un poco antes del proyecto de vivienda, la cooperativa había comprado diez vacas lecheras que rotaban entre las familias. Una vez se reubicaron, se presentaron dos situaciones que abrieron la puerta para la venta de las reses. Por una parte, la reubicación estaba evidentemente relacionada con la decisión ya tomada por la junta directiva — según la legislación hondureña, solo los hombres jefes de hogar podían ser socios de las cooperativas $^{18}$ - de dedicarse únicamente a la producción de palma africana. Tener las vacas no solo distraía a los miembros (a los hombres) de sus sueños palmeros (a mayor extensión de tierras con palma, mayor ingreso), sino que tampoco había dónde mantenerlas, ya que en el nuevo espacio doméstico no había terrenos

18 Este es un punto importante. Como Deere y León (2001) han mostrado, el acceso a la tierra
a través de la reforma agraria ha sido una quimera para las mujeres. Por ejemplo, para el
caso de la reforma agraria hondureña, solo un 3,8\% de las beneficiarias fueron mujeres (191). 
colectivos. Dicho en otras palabras, con el monocultivo, la idea de formas alternativas y diversas de producción va perdiendo sentido (Caffentzis y Federici 2013; Shiva 1993). Eugenia me cuenta que las discusiones sobre estos temas se daban únicamente entre los hombres sin consultarles nada a las mujeres. Sin embargo,

[...] pues cuando ya van a vender las vacas, quieren vender las vacas y caigo yo peleando nada. Hoy me doy cuenta que yo peleaba nada, yo no era socia (risas), el socio era él... Y yo entro y digo: - No, no van a vender las vacas. Yo hablé con el presidente, le digo yo:-Ay, ¿usted por qué van a vender las vacas...? No vendan las vacas, mire a cuántos niños les van a quitar la leche... Si venden la leche, ¿cómo van a tomar leche estos niños...? Mire, mire... Era Paulino, se llamaba el presidente... - Mire Paulino, yo digo que lo mejor no es vender las vacas, lo mejor es buscar otra alternita, ¿cómo vender esas vacas? A lo que el presidente respondió: - Mire, lo que está decidido está decidido, así que nadie lo puede evitar.

Ante esta imposibilidad de hacer recapacitar a la directiva, Eugenia buscó apoyo en las demás mujeres de la cooperativa:

Y mire que yo me acuerdo, agarro yo y les digo a unas mujeres: - $\mathrm{Mu}$ jeres, no dejemos vender las vacas... Y empiezo yo, les digo: -Denme el dinero, yo voy denunciar esto en Radio Tocoa. Y me da risa porque nada andaba haciendo yo, nada andaba haciendo... Pues hablando [en la radio] que sí, que la cooperativa vende las vacas y según yo denunciando (risas), pero eso no me valió de nada [...]

Al final fue imposible detener la venta de las vacas que fueron dadas a precio de ganga, por mucho menos de su valor. Sin embargo, para Eugenia el problema de las vacas tenía poco que ver con el dinero, se trataba más bien del impacto que tenía sobre el control y la capacidad de abastecimiento de las familias; es decir, de lo "común”19. Las vacas eran una marca material y concreta del alejamiento de sus prácticas comunitarias anteriores, significaban que, faltara lo que faltara, habría leche para sus hijos. Para ella, como para las demás mujeres, la fórmula de más palmeras igual más dinero, igual bienestar, significaba poco sin la seguridad tangible y colectiva de las vacas.

Poco después de la venta de las vacas hubo un cambio en la directiva de la cooperativa, y si a la anterior le había tocado la venta del ganado, a la nueva apropiación y reapropiación de lo que hay y de lo que es hecho, de lo que existe y de lo que es creado, de lo que es ofrecido y generado por la propia Pacha Mama y, también, de lo que a partir de ello ha sido producido, construido y logrado por la articulación y el esfuerzo común de hombres y mujeres situados histórica y geográficamente" (129). 
le tocaría la venta de las tierras. Al igual que en otras cooperativas en la región, la idea de vender las tierras había empezado algún tiempo antes de que se cristalizara hacia mediados de los noventa. De acuerdo con Martino, la razón detrás de la venta tenía que ver con problemas internos, puesto que la cooperativa ya había pagado sus deudas. Fundamentalmente varios de los socios consideraban que les estaban pagando muy poco por la producción y que había miembros que no trabajaban pero igual cobraban. Al mismo tiempo, varias cooperativas cercanas ya habían vendido, por lo que querían ver cuánto les darían por sus tierras. En este sentido, la idea de vender las tierras de la cooperativa no se puede ver de una manera aislada, sino como parte de un proceso más generalizado de despojo y transferencia de las tierras de la reforma agraria hacia las manos de un limitado número de empresarios nacionales y extranjeros. Estas discusiones iniciales, y la información sobre las posibilidades de venta, siempre se llevaban a cabo en las palmeras, para asegurarse de que las mujeres no se dieran cuenta ya que, según Eugenia, les preocupaba que si ellas se enteraban se opusieran a la venta. Martino recuerda que de los cuarenta y tantos socios que tenía la cooperativa, solo ocho estaban en contra:

Entonces nosotros que no estábamos de acuerdo, los ocho que no estábamos de acuerdo dijimos de que no, que no estábamos de acuerdo. Si querían que la cooperativa se vendiera, pues mejor que era repartir lo que nos tocaba y en la cuenta de nosotros nos tocaba como doce hectáreas cada uno y mejor repartamos la cooperativa... Y entonces dijo uno de ellos, de los que en ese tiempo, dijo uno: "No, con esa arma que tenemos, dice, el hijo de tanta que se atraviese por la venta de la cooperativa, dijo, lo vamos a hacer cortado porque no se puede más”, dijo. “No puede ser”, dijo, “que por uno o dos se pare la venta de la cooperativa, así es que el que se atraviesa solo eso le decimos...”.

Al final, y debido en buena medida a estas amenazas, se tomó la decisión de vender las tierras. Eugenia sabía de todo esto porque Martino le contaba sobre las reuniones. Una vez que supo que se había definido la venta, decidió hacer algo al respecto. Al igual que en el caso de las vacas e intuyendo que la relación con la tierra tenía mucho que ver con el género, volvió a buscar a las demás mujeres.

Pues vengo yo y reuní como a cinco mujeres y llamo y les digo: “Miren compañeras, no hay que vender la cooperativa, metámonos a que no vendan; miren, ¿qué vamos a hacer? ¿Qué vamos a hacer con este poco de hijos? ¿Cómo vamos a comer? ¿Dónde vamos a hallar dónde sembrar maíz para mantener a los hijos? ¡Miren qué poco de niños tenemos, niñas!”.

Para ella la tierra tenía poco o nada que ver con la corrupción de la cooperativa, con los precios pagados por el fruto de la palma o la cantidad de trabajo 
desigual. Para ella la tierra tenía que ver con la capacidad de abastecimiento de su familia. Esta posición no tenía que ver con no saber lo que pasaba en la cooperativa pues Martino, a diferencia de la mayoría de los hombres, siempre le contaba todo. Más bien tenía que ver con el hecho de que su relación con la tierra, en general la relación de las mujeres con la tierra, no estaba mediada por el dinero, como sí sucedía con los hombres y, por tanto, estaba más interesada en esos otros usos y relaciones que tenía y que potencialmente podía tener (como lo indica su mención a la posibilidad de sembrar maíz). Esto refuerza un punto que ya señalé y que me parece vital: la forma en que Eugenia y otras mujeres con las que conversé narran estos eventos contrasta con la versión de Martino y la de otros hombres con los que pude hablar. Evidentemente, este contraste está mediado por diferentes factores, incluyendo la socialización y los roles tradicionales de género existentes en el campo hondureño. No obstante, es importante subrayar que también nacen de una experiencia diferenciada en lo que respecta no solo a las ventas de las tierras, sino también a la relación que hombres y mujeres tenían con la tierra, con las cooperativas y con las dinámicas domésticas. Es decir, si bien podemos hablar del proceso de despojo de tierras como un tema de experiencia compartida de clase — todas las familias campesinas-, debemos tener claro que, en este caso, el género no solo es la modalidad en la cual se vivió la clase (Hall 1996), sino que también es aquella en que se recuerda el despojo (Hart 2006). Dicho en otras palabras, si bien el proceso de contrarreforma agraria fue vivido de manera conjunta por hombres y mujeres, las particularidades de dicha vivencia también estuvieron diferenciadas por género (y también por edad y etnia), lo cual dejó un vívido registro en las formas en que las distintas personas recuerdan dicho proceso.

Con respecto a su cruzada en contra de la venta de las tierras, Eugenia recuerda:

[las otras mujeres] me dieron cinco lempiras ${ }^{20}$ cada una (risas) para que yo me fuera a buscar de que alguien nos asesorara para que vinieran a hablar con los directivos de que no vendieran las tierras... Miren, no pudimos hallar. Yo fui a los Leones, me dijeron: "Mire, en eso nosotros no nos podemos meter porque es cooperativa aparte”. De allí busqué, me fui para Salamá... Y de allí me fui para Tocoa con un sacerdote. "Mire Juanito, yo quiero que me apoye, yo no quiero que vendamos las tierras, le digo yo, voy a buscar medios para poder”. Le he pedido que me llevara allá por Hondupalma, allá de Progreso, una aceitera que hay por ahí. Y yo llego desesperada y: "Miren señores, yo vengo a esto y a esto, que me apoyen que yo no quiero que vendan las tierras. Habemos 
bastantes mujeres que no queremos vender las tierras”. Y me dice: "Mire, si nosotros pudiéramos llegarle, pero esta gente ya está decidida”. Y claro, verdad, ellos pensaban que podían tener problemas pero yo no me doy cuenta pues de eso, yo no estoy preguntándome qué podía pasar.

Lo que podía pasar se volvió bastante palpable solo unas semanas después, cuando Martino era el único miembro que se negaba a firmar la venta de las tierras. Eugenia describe la situación: Martino estaba parado cerca de un árbol en la esquina de su propiedad afilando un machete,

[...] cuando viene un socio: - Buenas, dice. -Buenas, le digo yo... - ¿Y Martino? —Allá está... Y se viene, pero le habló bajito, yo no oí qué le dijo... ya cuando él se fue, le digo yo: —¿Qué te dijo? —Dice, me dijo, que vaya a firmar porque si no voy a firmar me van a matar...

Ella estaba inconsolable. Para ella perder la tierra significaba perder prácticamente todo:

Mire, yo lloraba, usted viera, yo quería ser unas miles de mujeres y poder parar esa venta de tierra. Porque no solo lo hacía por mí, sino ver un montón, usted, un montón... El que no hacía milpa era porque no quería y las matas de maíz que se sembraba se daban frondosas, era una bendición de Dios cosechar maíz. Teníamos maíz para comer, teníamos maíz para criar animalitos y no... Vendieron la tierra...

Aunque esta narrativa contrasta con lo que estaba pasando en ese momento - para cuando se vendieron las tierras la cooperativa solo producía palma-, es evidente que para Eugenia existía una correlación entre las posiciones de género y el continuo entre autoabastecimiento y trabajo asalariado; para ella, sin duda, la venta había sido una cuestión de los hombres. Esta correlación funciona a la vez como un hilo desde el cual articular los tres golpes descritos. Primero, con la reubicación de las viviendas se daba una separación física de los espacios domésticos y las palmeras - y con ella, de los espacios comunitarios “públicos” y domésticos "privados"-, lo que allanaba el camino para la venta de las tierras, a la vez que separaba a las mujeres de la tierra y profundizaba la dependencia de las unidades domésticas del mercado y los salarios de los hombres. Adicionalmente, limitaba la capacidad de las mujeres de reclamar sus derechos sobre la tierra, debido a tal dependencia y a su poca participación en las cooperativas por no ser socias. Segundo, la venta de las vacas aumentaba aún más la dependencia del trabajo asalariado, en contra del autoabastecimiento. Sin las vacas $-\mathrm{y}$ con toda la tierra cubierta con palma - prácticamente todo el abastecimiento de las unidades domésticas pasaba a estar mediado por el mercado, es decir, por los 
hombres. Finalmente, la venta de las tierras venía a ser la conclusión lógica de todo el proceso. La reacción de Eugenia con respecto al dinero que recibieron es reveladora:

-Ese dinero, le digo [a Martino], no lo vayas a meter a la casa, mételo al banco. Mire, yo no quería saber nada de aquel dinero. Yo no quería saber nada jay Dios! Mire hermano, las mujeres, le digo, que los hombres de la venta de tierra eran cuenterías, compraron sus armas, compraron... ¡Ah, se volvieron locos! Se volvió loca la gente. Y yo les decía, algunas cuando yo encontraba: —¿Andan aquí en Tocoa? —Sí, es que vinimos aquí a comprar... - Cuiden sus pistos [dinero] gente... Cuando ya se terminó el pisto, entonces sí decían:-¡iAh! Es que yo no estaba de acuerdo de que vendieran la tierra, decían, es que yo no estaba de acuerdo... Y si usted va a preguntar ahora nadie estaba de acuerdo de que vendieran la tierra... ¡Vaya pregunte! ¡Nadie! Dicen:-Ah, es que yo no estaba de acuerdo... Claro, es que ya no tienen nada... Pero sí, fue terrible y yo me enfermé de eso...

Mientras la mayoría de las personas gastaba su dinero - el equivalente a unos 750 dólares por familia - en consumo individual, Eugenia no quería saber nada al respecto, para ella ese era dinero sucio porque venía de la pérdida de la tierra - y de su vínculo con el autoabastecimiento- lo cual no podía ser reemplazado. Por ejemplo, la casa en la que vive actualmente es de bloques de cemento y techo de zinc, pero ella es muy enfática en hacerme saber que las mejoras vienen del trabajo de su familia y no del dinero de la venta de la tierra. Al respecto, hace además una profunda reflexión:

Pero la vida es diferente, diferente no tener un pedazo de tierra. ¡Es diferente! Y es terrible. Jamás, jamás, no le digo, pues, que desde que vendieron la tierra nosotros no conocemos una mazorca de maíz, no, una mata de maíz no conocemos. Solo comprando, primero Maseca ${ }^{21}$. Ahora ya mejor ideamos comprar la arroba de maíz o el quintal de maíz pero ahí vamos, ahí vamos... Como dicen, de hambre nadie muere, pero no, jamás es igual... Mire la leña, yo todavía, mire, ¿sabe qué les dije una vez en una reunión, porque ellos iban a trabajar y yo pasé a traer agua donde estaban reunidos, allá en el Bajo...? Les digo: -Mire, hombre, dejen de hablar de ventas de tierra, hombres, le digo, miren si usted, ¿le puedo decir algo? Cuando ustedes vendan las tierras no van a poder ni venir a sacar un pedazo de leña y ahorita, ahorita nosotros vamos a traer nuestra leña y vamos a pescar adonde nosotros queramos, se van a acordar cuando ustedes vendan las tierra. - iAh, es que usted no se meta a hablar! ¡Usted no sabe, mujer! -Ah, vayan pues... Mire ahora, 
mire ahora... Allá, el que va a sacar un pedazo de palo, allá se queda. Hoy hay pescado, creo yo, porque nadie va a pescar, el que va a pescar tiene problemas. Eso fue terrible, la vida, no tener tierra es bien difícil, porque con la tierra por mucho que solo milpita haga y sus frijolitos, pero uno solo tiene sus frijoles y su maíz. Pero así es bien difícil. Y lo bueno que ellos entonces, ellos peleando entre ellos mismos, peleándose fuertemente para que les dejara su pedazo de tierra para milpa. Porque también ellos querían meterle palma a todo, pero es cuestión de egoísmo, ¿verdad? Pero no, ellos en sus pleitecitos siempre lograban dejar sus pedazos de tierra para hacer su milpa. Teníamos milpa, teníamos guineo, yuca, platanera... Mire, es que era una bendición de Dios. Imagínese que los plátanos quién dice que los íbamos a comprar a tres, a cuatro pesos el plátano, ¡n’hombre! Si van a cortar dicen: "Hoy corté plátano...”. Me llevaban los grandes verdes y los pequeñitos, ay hombre, ahí se podrían los plátanos... Aparte de lo que nosotros teníamos, cada quien tenía sus chacas sembradas... Entonces eso es lo más bello, tener su tierra, pero sin tierra... Mire ahora, hoy estamos... Le digo yo:-Anda a ver quién te da un pedazo de tierra por ahí para hacer milpa... Dice que le da pena... Después de tener tierra y andar buscando, no, no, no... -Mejor no hago nada, dice...

\section{A manera de cierre: ¿qué es lo que se acumula a través del despojo?}

Hasta este momento hemos observado una pequeña parte de la historia de Eugenia y Martino y de su travesía desde su lugar de nacimiento en Copán, hasta el Bajo Aguán, Honduras. Esta travesía es de constantes cambios en términos de su posición de clase: pasaron de ser campesinos sin tierra a ser campesinos pobres en Atlántida, para volver a ser campesinos sin tierra, y de allí a miembros de cooperativa y, en el caso de Martino, a transportista. Es además, y sobre todo, una historia de pobreza marcada por un proceso de despojo diferenciado en términos de género.

De acuerdo con Marx (1993), en los Grundrisse, lo que se acumula dentro del capitalismo no es otra cosa que el trabajo humano. Dicho trabajo toma dos formas que están interconectadas: por un lado, el trabajo objetivado —o pretérito-, que se refiere a aquel trabajo que ya ha sido utilizado para la producción de mercancías y la transformación del paisaje. Por el otro, el trabajo viviente 
de aquellas personas que - potencialmente- pueden convertirse en trabajadoras. La palabra fundamental acá es potencialmente; ya regresaré a esto. Si dicha acumulación se da mediante los mecanismos del mercado, estamos frente a un proceso de acumulación ampliada de capital; si más bien el proceso se da mediante procesos no mercantiles - como la coerción directa, el pillaje, la estafa y el robo-, nos encontramos entonces frente al proceso de acumulación primitiva. En lo que sigue nos concentraremos en este segundo momento o proceso.

La fase de contrarreforma agraria hondureña tiende a ser vista como de alienación y concentración de la tierra. Sin embargo, esto es solo una parte. Enormes cantidades de trabajo objetivado también habían sido literalmente "ancladas” en la región, en forma de carreteras, diques, casas, plantas extractoras, pozos de agua, entre otros. Además, grandes sumas de inversión pública fueron destinadas a la preparación de las plantaciones de palma africana. Por ejemplo, para el caso del proyecto Bajo Aguán, se calcula que 11.000 ha de palma fueron sembradas con un costo inicial de 100 millones de dólares, lo que incluía la infraestructura necesaria para el desarrollo de la industria (carreteras, el puerto en Puerto Castilla, plantas extractoras), así como los terrenos preparados para plantar (Pino, Santacreo y Dunnaway 2002). Además, se debe incluir la inversión en educación que se hizo para preparar a varios cooperativistas y a sus hijos en el manejo técnico de la maquinaria y del proceso productivo, que incluyó becas universitarias y visitas a países como Israel para conocer el sistema cooperativo de ese país. También es importante resaltar que la mayor parte del trabajo de desmonte y siembra de las plantaciones fue hecho por las cooperativas prácticamente gratis, al mismo tiempo que estas tenían que pagar sus deudas con el Estado.

Un último punto a agregar tiene que ver con la producción misma de las palmeras. En términos históricos, la tendencia al crecimiento de la producción hondureña de palma africana empezó a mediados de 1980, pero la curva de crecimiento aumentó mucho más hacia finales de 1990. Tomando en cuenta que una palmera se demora dos años en producir y que llega a su pico productivo entre los siete y diez años, es claro que el desarrollo y la consolidación de la industria a partir de los años noventa - y en manos privadas - es el resultado directo del trabajo de las cooperativas. En otras palabras, junto con los precios de ganga que pagaron los terratenientes y empresas transnacionales por las tierras de la reforma agraria venían, a manera de promoción o de extra, una gran cantidad de inversión pública y trabajo objetivado. Es decir, el desarrollo del sector palmero hondureño actual, así como las exorbitantes riquezas generadas por algunas de las empresas más importantes de la industria, tales como Dinant, Grupo Jaremar 
y Aceydesa, no se puede entender sin el proceso previo de promoción estatal de la industria ni el proceso de acumulación primitiva de la contrarreforma agraria.

Además, hay que considerar el trabajo viviente que fue acumulado en este proceso. Esto no se refiere - como se tiende a pensar- simplemente a la separación de los potenciales trabajadores de los medios de producción y, por tanto, de sus formas de autoabastecimiento. Para que una persona venda su fuerza de trabajo no es suficiente liberarlo de la tierra -la migración siempre ha sido una alternativa-; es necesario además convertirlo en un sujeto bajo el control del capital, es decir, volverlo un trabajador (Moulier-Boutang 2006). En el caso del Bajo Aguán y de la industria palmera, esto significaba necesariamente la creación de un sujeto distinto al tradicional campesino hondureño como hasta ahora ha sido entendido. El nuevo trabajador debía estar atado a un lugar y dispuesto a trabajar de forma colectiva con respecto a la disciplina y las temporalidades determinadas por la industria palmera. También era necesario que este nuevo sujeto trabajador conociera y entendiera el cultivo de la palma africana y lo asumiera como propio; que conociera el vocabulario y las formas de plantar; cosechar y cuidar las palmeras era una condición fundamental para el florecimiento de la industria. Junto con las tierras de saldo y el trabajo objetivado, la contrarreforma les traspasó o les dejó a los terratenientes y empresas una fuerza de trabajo educada en la producción palmera y “libre” para vender su fuerza de trabajo. Así, de una u otra forma, el ciclo que había empezado en el caso de la familia de Eugenia y Martino se cerró con su huida de Copán: de pobres y sin tierra a pobres y sin tierra, pero versados en el monocultivo de la palma.

En este sentido, es útil pensar en el proceso de acumulación primitiva como una constante dentro de los procesos de acumulación de capital (De Angelis 2004; Perelman 2000). Constante que a su vez tiende a mostrar una tendencia cíclica (Grandia 2009), pero que no debe ser entendida en términos teleológicos:

Necesariamente, cada uno de estos nuevos ciclos es transformado por las formaciones sociales preexistentes y las particularidades locales y regionales, estas incluyen formas tradicionales y formales de tenencia sobre la tierra, configuraciones históricas de las relaciones de clase, redes de parentesco, patrones de género y de asentamiento, características ambientales, infraestructura existente o potencialmente existente, políticas públicas, acuerdos y tratados internacionales, así como formas de inserción en los mercados, entre otros elementos. (Edelman y León 2014, 196)

Es decir, si bien podemos hablar de una tendencia en el desarrollo histórico del capitalismo hacia la acumulación de trabajo humano (pretérito y viviente) por medios ajenos a las dinámicas mercantiles (la así llamada acumulación 
ampliada), la forma que toma este proceso depende de las características sociohistóricas y geográficas de cada contexto. Para el caso de Eugenia y Martino, estos ciclos son exactamente los que marcaron las etapas de su vida en pareja en el tiempo. El proceso de concentración y despojo de tierras que se vivió en el occidente de Honduras en la década de los sesenta transformó las instituciones tradicionales en las que habían vivido sus antepasados y los obligó a iniciar un proceso de migración que eventualmente los conectó con la reforma agraria hondureña y el proyecto del Bajo Aguán.

Dicha reforma agraria - las reformas agrarias en general- suelen ser entendidas como procesos contrarios al despojo, ya que más bien distribuyen tierras entre los grupos subalternos. Sin embargo, en el caso hondureño, su desarrollo y articulación con la industria de la palma africana generó las condiciones de posibilidad para que el siguiente ciclo de acumulación primitiva —el proceso de contrarreforma agraria de los noventa - tomara la forma que tomó.

Dejar este análisis acá sería repetir lo que Silvia Federici (2004), en su obra Calibán y la bruja, ha denominado como la limitación más grande de Marx - y sus seguidores - con respecto a la manera en que ha entendido el proceso de acumulación primitiva: ignorando y, por tanto, invisibilizando la experiencia particular y diferenciada de las mujeres. Para Federici la acumulación primitiva debe ser entendida no solo como un proceso constante de separación de las clases trabajadoras de los medios de producción, sino también, y al mismo tiempo, como un proceso constante de subordinación femenina, al separar a las mujeres de las esferas remuneradas de producción y enclaustrarlas en el espacio doméstico, bajo la etiqueta de reproductoras de la fuerza de trabajo. Como ya he mencionado varias veces, la diferenciación de género fue y sigue siendo central para el proceso de despojo. Con esto no quiero decir simplemente que la experiencia del proceso es distinta para hombres y mujeres, sino más bien que el proceso mismo vino a transformar las relaciones entre ellos y a crear una distinción entre trabajo productivo/remunerado y trabajo reproductivo/no-remunerado. En palabras de Judith Carney y Michael Watts (1990), “[...] las relaciones externas de producción [...] son modeladas y formadas por los procesos sociales internos (domésticos); en otras palabras, las luchas en el punto de producción son interiorizadas o más bien ‘domesticadas'” (211).

En el caso del Aguán, el despojo fue domesticado mediante el eje de la monetización y, en términos más específicos, a través del balance entre autoabastecimiento y trabajo asalariado. El proceso de organización de las cooperativas se tradujo en que las unidades domésticas tuvieron que acudir cada vez más al mercado para asegurar su abastecimiento. Esto a su vez profundizó la dependencia 
de las mujeres con respecto a sus esposos en dos direcciones: por un lado, en términos prácticos, las mujeres estaban bloqueadas tanto del trabajo remunerado como de la propiedad, ya que con la muy limitada excepción de las unidades domésticas lideradas por mujeres solteras, solo los hombres podían ser miembros de las cooperativas de reforma agraria. Por el otro, con la monetización vino la separación entre producción y reproducción, la cual se inscribió literalmente en los paisajes del despojo cotidiano (Ojeda et al. 2015), como lo muestra de forma tan enfática la historia de Eugenia. Con esto, la posición de las mujeres con respecto a las cooperativas y sus espacios comunitarios también se transformó. En un proceso similar al descrito por Rosario Montoya (2003), la separación de los espacios de producción de los de reproducción se tradujo en la separación entre los espacios públicos y privados, y se confinó a las mujeres a los segundos, lo que repercutió en su capacidad de acción política sobre los espacios comunitarios y colectivos.

En esta línea, me gustaría cerrar con una hipótesis que me parece ha sido poco explorada, aunque observada de manera empírica en muchas ocasiones. Uno de los argumentos centrales de Federici (2004) es que una de las razones centrales detrás de la cacería de brujas — del ataque tan agresivo contra las mujeres durante el periodo medieval en términos más generales- era reducir su presencia al frente de la lucha revolucionaria que se estaba llevando en contra de las clases feudales en ese momento (lucha frente a la cual el capitalismo y el ascenso burgués representan una contrarrevolución conservadora, según la autora). De acuerdo con Federici, el género era fundamental para el proceso de acumulación primitiva porque aseguraba un cierto tipo de dominación masculina que venía a controlar o limitar el potencial revolucionario de las mujeres. A partir de la historia de Eugenia, y en particular de su lucha contra las ventas de las tierras, se puede presentar un argumento similar. Al separar a las mujeres de la tierra y al limitar su posición social a la de amas de casa encerradas en el espacio doméstico en las comunidades, se las ubicaba, estructuralmente, en una situación desde la cual era prácticamente imposible afectar el espacio político de las cooperativas y, por tanto, detener las ventas. En este sentido, la definición del beneficiario en la mayoría de las reformas agrarias en América Latina como un sujeto masculino, jefe de una familia nuclear, sembraba las semillas de su propia destrucción.

Acá, y como en todo caso, esta idea del potencial revolucionario femenino debe ser leída dentro del contexto específico en el cual se presenta la pugna política. El hecho de que, debido a un conjunto de procesos particulares, las mujeres estuvieran ubicadas con respecto a la tierra de manera tal que los argumentos económicos o de corte más empresarial no tuvieran mayor influencia las hacía 
sumamente peligrosas para el proceso de despojo de la contrarreforma agraria. Para ellas, el mercado y su apetito de ganancias y relaciones aritméticas y abstractas se presentaba de una manera poco inteligible frente al peso y la importancia de asegurar el control concreto sobre el abastecimiento. En este sentido, podemos pensar en su lucha desde la perspectiva de lo que Raquel Gutiérrez $(2015,126)$ ha denominado la política en femenino:

[...] en tanto es una política que no ambiciona gestionar la acumulación del capital [...] sino que, básicamente, se afianza en la defensa de lo común, disloca la capacidad de mando e imposición del capital y del Estado y pluraliza y amplifica múltiples capacidades sociales de intervención y decisión sobre asuntos públicos.

Por otra parte, el sociólogo holandés Jan Douwe van der Ploeg (2010) ha propuesto que tal vez el único elemento que unifica a todos los campesinados del mundo es la lucha por la autonomía, entendida como un constante esfuerzo por mantener un cierto control sobre la base de recursos. Con base en el caso del Aguán, yo plantearía que dicha autonomía también tiene que ser entendida en términos de género. Mientras que las mujeres, a partir de su experiencia en tanto “cuidadoras”, tendían a entender la autonomía como un proyecto colectivo -algo que en términos generales lo vuelve algo ilegible para las lógicas liberales tanto del Estado como del mercado (Caffentzis y Federici 2013; Holloway 2011)-, los hombres, en tanto trabajadores y proveedores, lo entendían más bien como un proyecto individual o cuando menos familiar.

Esta diferencia nos invita, al menos, a repensar las perspectivas desde las que observamos e intentamos explicar esos temas tan amplios como el despojo, el Estado o el mercado, y verlos desde otras posiciones algo ocultas e insólitas y que tienden a ser invisibilizadas, pero desde las cuales podemos vislumbrarlas de forma distinta, potencialmente menos penumbrosa. Hoy en día, son mujeres que tuvieron a personas como Eugenia de maestras las que están al frente de las luchas en contra del despojo y a favor de un Aguán y una Honduras más habitables. Sin embargo, también son las que reciben la mayor parte de la violencia, tanto estatal como de los hombres de sus propias organizaciones. La lección parece ser clara: si no tomamos en cuenta las formas en las cuales las dinámicas de despojo y subordinación son domesticadas, difícilmente vamos a entender cómo subvertirlas. 


\section{Referencias}

Amaya Amador, Ramón. 1988. Destacamento rojo. Tegucigalpa: Universidad Nacional Autónoma de Honduras, Editorial Universitaria.

Anderson, Thomas P. 1983. The War of the Dispossessed: Honduras and El Salvador. Lincoln: University of Nebraska Press.

Arizpe, Lourdes. 1980. Migración por relevos y la producción social del campesinado. Serie Cuadernos del CES. México D. F.: El Colegio de México, Centro de Estudios Sociológicos.

Barahona, Marvin. 2005. Honduras en el siglo XX: una síntesis histórica. Tegucigalpa: Guaymuras.

Behrman, Julia, Ruth Meinzen-Dick y Agnes Quisumbing. 2012. "The Gender Implications of Large-Scale Land Deals”. Journal of Peasant Studies 39 (1): 49-79.

Bourdieu, Pierre. 2008. The Bachelors' Ball: The Crisis of Peasant Society in Bearn. Traducido por Richard Nice. Chicago: University of Chicago Press.

Boyer, Jefferson. 1982. “Agrarian Capitalism and Peasant Praxis in Southern Honduras”. Tesis doctoral, Department of Anthropology, University of North Carolina, Chapel Hill.

Brewer, Rose. 1999. "Theorizing Race, Class and Gender: The New Scholarship of Black Feminist Intellectuals and Black Women’s Labor”. Race, Gender \& Class 6 (2): 29-47.

Bulmer-Thomas, Victor. 2003. The Economic History of Latin America since Independence. 2. ${ }^{\mathrm{a}}$ ed. Nueva York: Cambridge University Press.

Cáceres, Miguel y Sucelinda Zelaya. 2005. "Honduras. Seguridad productiva y crecimiento económico: la función económica del cariato”. Anuario de Estudios Centroamericanos 31: 49-91.

Caffentzis, George y Silvia Federici. 2013. “Commons against and beyond Capitalism”. Upping the Anti 15: 83-91.

Carney, Judith y Michael Watts. 1990. "Manufacturing Dissent: Work, Gender and the Politics of Meaning in a Peasant Society”. Africa 60 (2): 207-241.

-. 1991. "Disciplining Women? Rice, Mechanization, and the Evolution of Mandinka Gender Relations in Senegambia”. Signs 16 (4): 651-681.

Casolo, Jennifer. 2009. “Gender Levees: Rethinking Women’s Land Rights in Northeastern Honduras”. Journal of Agrarian Change 9 (3): 392-420.

Castro, Ángel Augusto. 1994. Un plan de desarrollo regional: el Bajo Aguán en Honduras. México D. F.: Universidad Iberoamericana.

Chapman, Anne. 1985. Los hijos del copal y la candela: ritos agrarios y tradición oral de los lencas de Honduras. México D. F.: Universidad Nacional Autónoma de México.

Chu, Jessica. 2011. "Gender and 'Land Grabbing' in Sub-Saharan Africa: Women's Land Rights and Customary Land Tenure”. Development 54 (1): 35-39.

Clare Rhoades, Patricia. 2011. Los cambios en la cadena de producción de la palma aceitera en el Pacífico costarricense: una historia económica, socioambiental y tecnocientífica, 19502007. San José: Sociedad Editora Alquimia 2000. 
Consejo Coordinador de Organizaciones Campesinas de Honduras (Cococh). 2010. "Reforma agraria, agricultura y medio rural en Honduras. La agenda pendiente del sector campesino”. Consultado el 6 de julio del 2014. http://www.landcoalition.org/pdf/08_cococh_Reforma_Agraria_en_Honduras.pdf.

Corley, R. Hereward y Philip Bernard Tinker. 2008. The Oil Palm. Nueva York: John Wiley \& Sons.

Courville, Michael, Raj Patel y Peter Rosset. 2006. Promised Land: Competing Visions of Agrarian Reform. Oakland: Food First Books.

Crehan, Kate. 1997. The Fractured Community: Landscapes of Power and Gender in Rural Zambia 54. Berkeley: University of California Press.

-. 2002. Gramsci, Culture and Anthropology. Berkeley: University of California Press.

De Angelis, Massimo. 2004. "Separating the Doing and the Deed: Capital and the Continuous Character of Enclosures”. Historical Materialism 12 (2): 57-87.

De Fontenay, Catherine. 1999. "Institutions, Market Power and the Big Push: The Case of Agro-Exports in Northern Honduras. University of New South Wales, School of Economics”. Consultado el 8 de junio del 2014. http://www.researchgate.net/publication/228790814_ Institutions_Market_Power_and_the_Big_Push_The_Case_of_Agro-exports_in_Northern_Honduras/file/60b7d521aeb579631e.pdf.

Deere, Carmen Diana y Magdalena León. 2001. Empowering Women: Land and Property Rights in Latin America. Pittsburgh: University of Pittsburgh Press.

Edelman, Marc y Andrés León. 2014. "Ciclos de acaparamiento de tierras en Centroamérica: un argumento a favor de historizar y un estudio de caso del Bajo Aguán, Honduras”. Anuario de Estudios Centroamericanos 40 (1): 195-228.

Euraque, Darío. 2001. El capitalismo de San Pedro Sula y la historia política hondureña (18701972). Tegucigalpa: Guaymuras.

Federici, Silvia. 2004. Caliban and the Witch. Nueva York: Autonomedia.

Fox, Robin. 2004. Sistemas de parentesco y matrimonio. Madrid: Alianza.

González, Nancie L. Solien. 1988. Sojourners of the Caribbean: Ethnogenesis and Ethnohistory of the Garifuna. Urbana: University of Illinois Press.

Gramsci, Antonio. 1999. Cuadernos de la cárcel. México D. F.: Ediciones Era.

Grandia, Liza. 2009. Despojo recurrente al pueblo Q'eqchi'. Ciudad de Guatemala: Asociación para el Avance de las Ciencias Sociales en Guatemala (Avancso).

Gutiérrez Aguilar, Raquel. 2015. "Políticas en femenino: transformaciones y subversiones no centradas en el Estado”. Contrapunto 7: 123-139.

Hall, Ruth, Marc Edelman, Saturnino Borras Jr., Ian Scoones, Ben White y Wendy Wolford. 2015. "Resistance, Acquiescence or Incorporation? An Introduction to Land Grabbing and Political Reactions from Below”. Journal of Peasant Studies 42 (3-4): 467-488.

Hall, Stuart. 1996. "Race, Articulation, and Societies Structured in Dominance”. En Black British Cultural Studies: A Reader, editado por Houston A. Baker Jr., Manthia Diawara y 
Ruth H. Lindeborg, 16-60. Consultado el 25 de agosto del 2014. http://books.google.es/book $\mathrm{s} ? \mathrm{hl}=\mathrm{en} \& \mathrm{lr}=\& \mathrm{id}=$ ceev $2 \mathrm{zRrKBgC} \& \mathrm{oi}=\mathrm{fnd} \& \mathrm{pg}=\mathrm{PA} 16 \& \mathrm{dq}=\mathrm{stuart}+\mathrm{hall}+\mathrm{on}+$ articulation $\&$ ots $=$ kz5GIffEyP\&sig=yhZHY_LRXyWNbwHnKShHG9E1Og4.

Hart, Gillian. 2006. "Denaturalizing Dispossession: Critical Ethnography in the Age of Resurgent Imperialism”. Antipode 38 (5): 977-1004.

Holloway, John. 2011. Agrietar el capitalismo. Barcelona: El Viejo Topo.

Jones, Jeffrey R. 1985. Colonization and Environment: Land Settlement Projects in Central America. Colonización y ambiente: proyectos de asentamientos en Centroamérica. Turrialba: Catie.

Kapuscinski, Ryszard. 1992. La guerra del fútbol y otros reportajes. Madrid: Anagrama.

Kay, Cristóbal. 1998. "Latin America's Agrarian Reform: Lights and Shadows”. Land Reform, Land Settlement and Cooperatives 2: 9-31.

Kerssen, Tanya M. 2013. Grabbing Power: The New Struggles for Land, Food and Democracy in Northern Honduras. Oakland: Food First Books.

Lara Ponce, Estuardo, Laura Caso Barrera y Mario Aliphat Fernández. 2012. "El sistema milpa roza, tumba y quema de los maya itzá de San Andrés y San José, Peten Guatemala”. Ra Ximhai 8 (2): 71-92.

Li, Tania Murray. 2011. “Centering Labor in the Land Grab Debate”. The Journal of Peasant Studies 38 (2): 281-298.

Macías, Miguel Alonzo. 2001. La capital de la contrarreforma agraria: el Bajo-Aguán de Honduras. Tegucigalpa: Guaymuras.

Mackintosh, Maureen. 1989. Gender, Class, and Rural Transition: Agribusiness and the Food Crisis in Senegal. Nueva Jersey: Zed Books Limited.

Martín-Baró, Ignacio. 1972. Psicodiagnóstico de América Latina. San Salvador: UCA Editores.

Marx, Karl. 1993. Grundrisse. Londres; Nueva York, N. Y: Penguin Adult.

Massey, Doreen. 2013. Space, Place and Gender. Cambridge: John Wiley \& Sons.

Massey, Douglas S., Joaquín Arango, Graeme Hugo, Ali Kouaouci y Adela Pellegrino. 1999. Worlds in Motion: Understanding International Migration at the End of the Millennium. Nueva York: Oxford University Press.

Metz, Brent. 2010. Questions of Indigeneity and the (Re)-Emergent Ch'orti'Maya of Honduras. The Journal of Latin American and Caribbean Anthropology 15 (2): 289-316.

Mintz, Sidney y Eric R. Wolf. 1950. “An Analysis of Ritual Co-Parenthood (Compadrazgo)”. Southwestern Journal of Anthropology 6 (4): 341-368.

Moctezuma Pérez, Sergio. 2006. La unidad doméstica dentro del proceso migratorio. México. Consultado el 30 de enero del 2015. http://cdigital.uv.mx/bitstream/123456789/9079/1/ ar1_p4-8_2010-6.pdf.

Montoya, Rosario. 2003. "House, Street, Collective: Revolutionary Geographies and Gender Transformation in Nicaragua, 1979-99”. Latin American Research Review 38 (2): 61-93. 
Moulier-Boutang, Yann. 2006. De la esclavitud al trabajo asalariado. Barcelona: Akal.

Ojeda, Diana. 2012. "Green Pretexts: Ecotourism, Neoliberal Conservation and Land Grabbing in Tayrona National Natural Park, Colombia”. Journal of Peasant Studies 39 (2): 357-375.

Ojeda, Diana, Jennifer Petzl, Catalina Quiroga, Ana Catalina Rodríguez y Juan Guillermo Rojas. 2015. "Paisajes del despojo cotidiano: acaparamiento de tierra y agua en Montes de María, Colombia”. Revista de Estudios Sociales 54: 107-119.

Organización de Estados Americanos (OEA). 1964. Informe oficial de la Misión 105 de asistencia técnica directa a Honduras sobre reforma agraria y desarrollo agrícola. Tomo III: Proyecto de colonización del Bajo Aguán. Washington D. C.: Organization of American States (OAS).

Perelman, Michael. 2000. The Invention of Capitalism: Classical Political Economy and the Secret History of Primitive Accumulation. Durham: Duke University Press.

Pino, Hugo Noé, Elizabeth Santacreo y Anna Dunnaway. 2002. Mesa Agrícola Hondureña Palma Africana. Secretaría de Agricultura y Ganadería (SAG).

Robertson, Alexander Foster. 1984. People and the State: An Anthropology of Planned Development. Cambridge: Cambridge University Press.

Robichaux, David. 2005. Familia y parentesco en México y Mesoamérica: unas miradas antropológicas, vol. 2. México D. F.: Universidad Iberoamericana.

—. 2008. "Sistemas familiares subalternos de América Latina y el Caribe: notas preliminares”. En Familias y culturas en el espacio latinoamericano, editado por Ana Vera Estrada y David Robichaux, 25-62. México D. F.: Universidad Iberoamericana.

Roquas, Esther. 2002. Stacked Law: Land, Property and Conflict in Honduras. Ámsterdam: Rozenberg.

Roux, Rhina. 2005. El príncipe mexicano: subalternidad, historia y Estado. México D. F.: Era.

Scott, Joan Wallach. 1999. Gender and the Politics of History. Nueva York: Columbia University Press.

Shiva, Vandana. 1993. Monocultures of the Mind: Perspectives on Biodiversity and Biotechnology. Nueva York: Palgrave Macmillan.

Simmel, Georg. 1978. The Philosophy of Money. Traducido por Tom Bottomore y David Frisby. Londres: Routledge \& Kegan Paul.

Smith, Neil. 2006. "There's no such Thing as a Natural Disaster. Understanding Katrina: Perspectives from the Social Sciences”. Consultado el 13 de julio del 2014. http://forums. ssrc.org/understandingkatrina/theres-no-such-thing-as-a-natural-disaster/.

Soluri, John. 2009. Banana Cultures: Agriculture, Consumption, and Environmental Change in Honduras and the United States. Austin: University of Texas Press.

Stolcke, Verena. 2010. “¿Qué tiene que ver el género con el parentesco?”. En Procreación, crianza y género. Aproximaciones antropológicas a la parentalidad, editado por Virginia Fons, Anna Piella y María Valdés, 319-334. Barcelona: Promociones y Publicaciones Universitarias. 
Thiesenhusen, William C. 1995. Broken Promises: Agrarian Reform and the Latin American Campesino. Nueva York: Westview Press.

Thompson, Edward P. 1967. “Time, Work-Discipline, and Industrial Capitalism”. Past and Present 38: 56-97.

Van der Ploeg, Jan Douwe. 2010. The Peasantries of the Twenty-First Century: Struggles for Autonomy and Sustainability in an Era of Empire and Globalization. Londres: Earthscan.

Watts, Michael. 2013. Silent Violence: Food, Famine, and Peasantry in Northern Nigeria. Vol. 15. Athens: University of Georgia Press.

Williams, Robert Gregory. 1986. Export Agriculture and the Crisis in Central America. Chapel Hill: UNC Press Books.

-. 1994. States and Social Evolution: Coffee and the Rise of National Governments in Central America. Chapel Hill: UNC Press Books.

Wolf, Eric. 1971. Los campesinos. Traducido por Juan-Eduardo Cirlot. Barcelona: Labor.

- 1980. "Relaciones de parentesco, de amistad y de patronazgo en las sociedades complejas". Antropología Social de las Sociedades Complejas: 19-39.

Yie, Maite. 2015. Del patrón-Estado al Estado patrón. Bogotá: Universidad Nacional de Colombia; Universidad Javeriana. 